\title{
Developing reflective function: the advocacy model as a way of developing a sense of meaning in young people
}

\author{
Brendan Schmidt \\ Doctoral candidate \\ Faculty of Education \\ La Trobe University \\ Melbourne, Australia \\ Bernie Neville \\ Adjunct Professor \\ Faculty of Education \\ La Trobe University \\ Melbourne, Australia
}

\begin{abstract}
The psychological development of children and adolescents, however broadly or narrowly conceived, is central to the purpose and function of schools. However, frequently insufficient attention is paid to a key aspect of psychological development in adolescence: the reflective function. This paper outlines the rationale for a specific systemic intervention in the schooling experience of adolescents. In a number of schools in Victoria the provision of one-to-one relationships between teacher-advocates and students is coupled with the use of a bank of electronic tools (the Student Achievement Inventory) designed to support the development of reflective function and with it the capacity to construct a meaningful experience of learning within the school context. We discuss the advocacy model within the framework of developmental psychology and attachment theory.
\end{abstract}

\section{Introduction}

The purpose of this paper is to outline the theoretical basis of a specific intervention currently being implemented in a number of Victorian schools. 
The 2009 How young people are faring report from the Foundation for Young Australians (Robinson and Lamb 2009) suggests that some of them are not faring very well. School completions are down. Youth unemployment is up. Early school leavers report poor satisfaction with their quality of life and poor psychological health compared with their peers, who are more likely to be studying or working. This is by no means a new situation, and it is predictable that the causes of these problems should be sought, in part, in the inadequacies of schooling. Teachers in the past decade have tried, with varying success, a number of different interventions to engage adolescents in schooling and ensure that they complete high school. The advocacy model described in this paper represents one such approach.

The advocacy model operates on the premise that psychological wellbeing, cognitive development and academic achievement are interrelated. Previous research on the model (Ocean 2001; Henry, Barty and Tregenza 2003) has provided evidence that the one-to-one relationship between a student and a teacher-advocate has a positive impact on both academic achievement and psycho-social wellbeing. This conclusion is consistent with the findings of a wide range of studies on the impact of teacher-student relationships on the wellbeing of children and adolescents. Such findings may be readily theorised within Carl Rogers' 'person-centred' theory of personality and behaviour (Rogers 1951, 1961, 1983).

The present paper addresses the specific issue of the adolescent development of autonomy and construction of meaning as an aspect of psychological development. These aspects of psychological development are inter-related with student perceptions of belonging and competence. We argue that student advocacy and the electronic tools designed to support it can facilitate the adolescent's development of mature reflection on their life experience. The rationale for this argument is drawn from attachment theory (Bowlby 1979; Knox 2003; Fonagy et al. 2005; Riley 2011). John Bowlby's original (1982) formulation of attachment theory focused on the relationship between infants and their primary caregivers. More recently researchers have turned their attention to the function of the attachment system over the life course, with a particular focus on adolescence (McElhaney et al. 2009; Allen and Land 1999; Rice 1990). Attachment theory argues that cognitive development and attachment are intrinsically related. We argue on the same grounds that just as the 'secure base' of parental attention (Bowlby 1990) provides the necessary context for the infant's acquisition of language, a secure base such as that provided by a competent and caring teacher-advocate is the necessary context for an adolescent's self-reflection and construction of meaning in the context of schooling. While there may be only a minority of students who have no primary caregivers able to provide a 'safe haven' and 'secure base', it must be acknowledged that in the adolescent search for 'the person I feel I can always count on', adults other than parents are often in the frame, and an adequately trained teacher-advocate may be the person most appropriate to fulfil this need.

Jean Knox (2003), who theorises within the framework of attachment theory, has made a significant contribution to our understanding of the adolescent construction of meaning. We not only suggest that attachment theory, developmental theory and person-centred theory overlap and interact, but propose further that adolescents' 
cognitive and emotional development, their construction of meaning, their psychosocial wellbeing and their engagement in schooling are interrelated.

\section{Background}

Since 2000, a number of state and Commonwealth reports have addressed the problems of adolescent disengagement from schooling, early school leaving and consequent unemployment and disengagement from society. These include the report of the Prime Minister's Youth Pathways Action Plan Taskforce (DEST 2001), the National Evaluation Report of the Full Service Schools Program 1999 and 2000 (DETYA 2001b), DETYA's Doing it well report on best practice in dealing with atrisk young people (2001a), the Victorian Department of Education's Kirby Report (Ministerial Review 2001), The Queensland DEA's Staying on at school report (Lamb et al. 2004), and the SA Dept of Premier and Cabinet's Making the connections School Retention Action Plan (Social Inclusion Unit 2006). These have provided a wide range of recommendations, ranging from early intervention literacy programs, through student support services, to school-to-work transition programs, many of which have been implemented.

A common thread in these reports has been the importance of establishing a positive learning experience for students in the middle and senior school. The importance of a one-to-one relationship with a caring adult in determining students' attitudes to schooling, their learning progress and decisions to complete their education, and indirectly - to avert undesirable behaviours such as substance abuse, is supported by a number of significant Australian studies (e.g. Holden and Dwyer 1992; Brooks et al. 1997; Stokes 2000 McIntyre et al. 1999). Australian and international studies have linked positive teacher-student relationships with school retention, and linked early school leaving with unemployment, unhappiness, poor health, substance abuse and the probability of incarceration (Rumberger 1987; Pomeroy 1999; Pettet and Western 2004; Drapela 2006; Fiscella and Kitzman 2009; Van Alphen 2009). Overviews of school reform programs in the search for common characteristics associated with effectiveness have pointed to one-to-one relationships between a student and an adult as an essential component of programs leading to positive outcomes (e.g. Fashola and Slavin 1998 Mukherjee 1999). Fraser et al.'s (1987) synthesis of previous meta-analyses of studies of school reform concluded that 'proximal' factors such as interactive student-teacher variables are more potent in school reform than more distal variables such as school aims and curriculum changes. They claimed there is empirical support that the empowerment of students in interaction with teachers is one of the best ways to improve student outcomes. This is especially the case where students 'at risk' are concerned (Baker et al. 1997). Likewise, on the basis of a review of studies conducted within the framework of cognitive psychology, Osterman (2000) argued that that lack of 'belongingness' consequent on inadequate teacher-student relationships is associated with mental and physical illness and behavioural problems. These, in turn, lead to lack of success at school. In contrast, positive involvement with teachers is associated with engagement, wellbeing and achievement.

Education authorities - federal, state and local - tend to prioritise 'distal' factors, over which they can assume some control. From an administrative point of view it is 
simpler to establish a new bureaucracy, modify a management structure or introduce a new curriculum than to change teachers' behaviour. This paper argues for a redress of the imbalance, with greater emphasis being given to the specific 'proximal' factor of the student-teacher relationship.

The advocacy model of student support has been developed within this context. The Advocacy Project (1998-2003), funded by the Victorian Department of Education, trialled certain components of the model, which were found to be efficacious in promoting school engagement and student wellbeing (Ocean 2001; Henry et al. 2003). There are two central components of the model. Firstly, it involves a one-toone relationship between a student and a teacher-advocate, who undertakes specific responsibilities with regard to that student. The label 'advocate' was adopted, rather than 'advisor' or 'mentor', to emphasise a particular aspect of the relationship, in that the teacher-advocate focuses on listening to the student to ensure that the student's voice is heard within the school. If the student is in conflict with a teacher or the school administration, the advocate will make sure that the student's perspective is taken seriously. This involves having an understanding of the student's background and motivation. Within this structure of support, the advocacy model requires the students to accept responsibility for their own progress. The second component of the model is an electronic Student Achievement Inventory (SAI) designed to assist the students, with the support of their advocates, to reflect on their purposes, achievements and school experience.

At its inception in 1998 the advocacy model was designed as a means of compensating for the lack of pastoral care resources in Victorian state schools in the 1990s. The proportion of students completing Year 12 in the state system had declined from 85 per cent to 65 per cent over this period, and it was argued that this was the result of the lessening of funds to assist with individual learning difficulties. The positive impact of advocacy was soon apparent in the evidence that students with advocates were more likely to remain at school, were more likely to attend school consistently and were likely to have better academic outcomes than comparable students without advocates (Ocean and Caulley 2000; Ocean 2001). Further experience with the model as implemented in Victorian schools suggests that the provision of a secure and reliable relationship with a teacher-advocate who engages with the student empathically and non-judgementally has a positive impact on the adolescent's emotional wellbeing (Henry et al. 2003) and psychological development (McCann 2008). These assessments of the impact of advocacy have demonstrated further that the one-to-one relationship is more powerful in this regard than either the 'good relationship' that many teachers can legitimately claim to have with their class, or arrangements in which an advocate or learning mentor talks with students as a group. Evidence suggests that the model 'works' best when the teacher-advocate is responsible for no more than twelve students whom he or she reliably meets for twenty minutes at fortnightly intervals.

The use of the electronic Student Achievement Inventory (www.sai.vic.edu.au) within an advocacy framework has the potential to further enhance adolescent psychological development and emotional wellbeing. 
A number of instruments developed overseas are currently available to record study attitudes and skills such as SAMS (Michael, Michael and Zimmerman 1985), PSRS (Karnes and Bean 1990), LASSI (Weinstein and Palmer 1990) and the SBI (Bliss and Mueller 1993; Bliss 2002). While there have been a number of studies of the utility of such self-assessment instruments in facilitating school achievement (Olivárez and Tallent-Runnel 1994; Everson, Weinstein and Laitusis 2000) none have focused on their use within the context of a structured supportive relationship such as advocacy.

The SAI includes online questionnaires relating to the student's interests, learning history, learning preferences, goals, attitudes to school discipline, as well as literacy, numeracy and study skills, as perceived by the students themselves. The immediate feedback provided to students is designed to help them recognise some aspects of themselves in a profile that highlights their strengths as well as their weaknesses. The database allows them to compare this profile as it changes over time. It also allows the school to profile the student population on a number of significant dimensions.

While these tools have been developed for students to use independently, informal trials suggest that they are also effective as triggers that enable students to talk more freely about themselves to the teacher-advocate. Conversely, the supportive relationship may assist the student to be honest in recognising the things they can change, and develop the confidence to do so.

\section{Reflective function and engagement}

Jean Knox argued that 'reflective function' is the root of our sense of meaning and capacity to symbolise. It begins to become clear that the concept of reflective function has enormous
implications for our understanding of human psychological development and
functioning and in particular for the development of a sense of meaning - a word that
we all intuitively understand but which a moment's reflection shows to be rather
vague and imprecise. What are the contributing factors to a sense of meaning, which
is rooted in the capacity to find symbolic significance in our experience? I would
suggest there are four key and interrelated elements, all of which contribute to the
development of reflective function:

1. Narrative competence: the recognition of psychological cause and effect, which links events in a meaningful way and is the basis for a sense of agency.

2. Intentionality: the capacity to pursue goals and desires, that is, to have a mental appetite.

3. Appraisal: the capacity to evaluate the relative significance of experiences.

4. Individuation: the awareness of one's own and other people's independent subjectivity. (2003, p. 42).

Knox based her argument on current understandings of developmental psychology and the related field of attachment theory. She prefers the term 'reflective function' to such terms as 'metacognitive monitoring' and 'mentalisation', which have been used by other writers to describe the awareness of oneself and others as independent psychological and emotional beings. On the one hand she proposed that the 
reflective function begins to emerge in children in their second year. On the other she argued that not everybody manages to develop an adequate reflective function, and hence they 'lack the capacity to empathize with other people or place their own emotions in a meaningful context, to reflect on them and so experience them in a safe way' (p. 139). They habitually treat themselves and others as objects, and are unable to give a reflective and coherent account of their lives. She made the case that this is a consequence of their failure to develop secure attachment as infants.

Insecure attachment as infants leads to insecure attachment as adolescents and adults. This is manifested in specific 'attachment styles' which attachment theorists identify as secure, anxious-preoccupied, dismissive-avoidant and fearful-avoidant (Bartholomew and Horowitz 1991; Fonagy et al. 2005; Riley 2011). However, insecure attachment styles are not set in stone from infancy. Knox herself is a Jungian analyst, and clearly believes, like Fonagy and his co-authors, in the capacity of the analytical process to counteract the effects of early destructive relationships. Working within a very different framework, Carl Rogers $(1951,1961,1983)$ argued that the therapist's provision of a relationship characterised by empathy, acceptance and congruence is of itself efficacious in giving the recipient the freedom to abandon self-destructive habits of mind and behaviour and move towards a more autonomous way of being.

There is some evidence that attachment styles are less stable in adolescence than in infancy and childhood, and that an aspect of adolescent development is the revision of internal working models (Ainsworth 1989; Allen and Land 1999; McElhaney et al. 2009). The reflective function is central to this aspect of adolescent cognitive development, as teenagers gain a greater capacity to compare relationships with different attachment figures.

In a comprehensive review of research on adolescent attachment, McElhaney et al. noted that the concept of autonomy 'is integrally embedded within the theory regarding the nature and function of attachment relationships' (2009, p. 359). There is, they noted, 'a continual balance between stress-reducing behaviours that incorporate dependence on the caregiver and exploratory behaviours that increase knowledge of and mastery over the environment' (ibid). In adolescence this is complicated by the shift in the young person's 'attachment hierarchy', in which primary caregivers lose their privileged place to peers, romantic partners and other significant adults such as teachers. Indeed, it has been argued that adolescents must relinquish childish dependencies on parents in order to become fully autonomous (Blos 1967). In this context we may suggest that a reliable and caring teacheradvocate may play a significant role in an adolescent's development of autonomy, even when the adolescent's childhood experience has been one of secure attachment.

Some adolescents will have 'attachment issues', grounded in infantile trauma or inadequate parenting, and can be helped to overcome them through the offering of secure relationships with adults and peers in a school setting. Others will be confidently secure in their relationships. Regardless of their starting point, both groups will be assisted in the development of the reflective function, and 
consequently of their capacity to construct a meaningful experience of schooling, if provided with a secure and reliable relationship with a committed teacher-advocate.

\section{Promoting a sense of meaning}

It can be argued that promoting a sense of meaning is the major focus of schooling, however that sense of meaning may be interpreted by schools. We will not be capable of engaging and continuing to engage students in their education if schooling is for them a meaningless activity.

What is the significance of an education? Why am I here? Where am I going? What am I doing? When does it have to be done? These are questions that adolescents ask as they progress through the education system. Schools that operate within a strong narrative, religious or secular, may be able to provide answers that satisfy some, at least, of their students. However, the education system seems largely unable to assist students towards a vision of life. The demands of a consumerist culture are not an adequate substitute for meaningful intention. As Knox pointed out:

There are many people who simply do not seem to know what they want, what interests them or excites their attention. They seem trapped in a passive prison in which they are doomed to respond endlessly to other people's demands on them, because the alternative is a terrifying emptiness and aimlessness born out of the absence of desire. (2003, p. 150)

In the schooling we provide we make constant demands on students regarding their behaviour and their achievement. We tend to prefer a mindless compliance to an authentic resistance. We offer little opportunity for students to gain meaning from the daily activities, the trials and the tribulations of participation in the education system. We offer little opportunity to engage in reflection on who they are as learners, develop intentions or reflect with a significant other upon achievement and what it might mean.

\section{The advocacy relationship}

If we are to engage young people in schooling there needs to be an active and systematic approach to the development of meaning. This requires a degree of understanding of the symbolic significance of the adolescent's experience: schooling, job, money, lifestyle, problem solving, peer culture. With this in view, teacher-advocates are provided with professional development in a Rogerian, 'person-centred' approach to interpersonal communication. Evaluations of earlier experiments with the advocacy model (Ocean 2001; Henry et al. 2003) have indicated that the model works best when the teacher-advocate not only provides a secure and reliable relationship (which may well be provided in a conventional teacher role) but focuses specifically on listening to the student rather than on directing, evaluating, reprimanding and advising - functions that teachers habitually exercise but which are counter to good practice in an advocacy role.

Carl Rogers developed a theory of personality and therapeutic change within a subjectivist paradigm, arguing that 'behaviour is basically the goal-directed attempt of the organism to satisfy its needs as experienced, in the field as perceived' (1951, 
p. 491) and 'the best vantage point for understanding behaviour is from the internal frame of reference of the individual himself [sic]' (p. 494). Within such an understanding we can argue that a particular student's self-destructive or anti-social behaviour is simply their way of dealing with 'the field as perceived'.

Rogers' research on therapeutic process led him to the conclusion that the quality of the relationship between therapist and client was critical. Only a relationship characterised by empathy, congruence (genuineness) and what he called 'unconditional positive regard' could provide the opportunity for the client to reflect freely on the nature of 'the field as perceived' and become aware of their capacity to choose their behaviour consciously rather than act out of habit or react mindlessly to their environment. Only such a relationship could provide an environment for the client's own development of empathy, genuineness and acceptance of others.

Though Rogers' thinking originally revolved around the relationship of therapist and client, he became aware that what was true of the therapeutic relationship was true of all relationships. Good relationships - between partners, between parents and children, between teachers and students - are characterised by empathy, genuineness and acceptance. This is especially critical in an explicitly supportive relationship such as advocacy.

Teachers are inclined to see counselling as involving specific professional skills, skills quite different from those in which they are themselves trained and experienced. They may be reluctant to embrace the advocate role if they see it as taking over the role of school counsellor. School counsellors, likewise, may not be inclined to look with favour on the introduction of the advocacy model if it looks as though untrained people are going to be involved in counselling students.

However, advocacy as understood here is not counselling, certainly not the kind of counselling that is conventionally seen as the norm in Australia: cognitive behavioural therapy. The focus of the advocate is on supporting the student's learning. The method of advocacy is to provide the student with a secure and reliable relationship in which an interested adult will listen non-judgementally to whatever the student has to say about their learning and the factors that affect it for better or for worse. It creates a situation in which someone in the school knows something of the student's aims and goals (or lack of them), the difficulties they face, and their life outside school. There is someone in the school who is able to intervene on the student's behalf when the school is reacting to 'bad behaviour' which, as far as the student is concerned, is simply 'the goal directed attempt to satisfy [their] needs as experienced in the field as perceived'.

Neither is advocacy teaching. Teachers instruct, advise, evaluate and, where necessary, reprimand or control the students in their classes. The role of advocate differs from this in significant ways. The advocate restrains the urge to direct, judge or reprimand, and concentrates on the attempt to understand how the student perceives the world of learning, and how he or she may be helped to connect with it. She even restrains her urge to give advice, acknowledging that the aim of helping students to become independent learners may be hindered by an over-eagerness to 
tell them what they should be doing. It is desirable to keep the roles of teacher and advocate separate, avoiding a situation where teachers are acting as advocates for students who are in their own classes.

\section{Advocacy and reflective function}

Within the advocacy model students can be provided with the opportunity to construct meaning for their participation in the education system and to discover how they might best use it to achieve personal goals. The advocacy model provides an approach whereby the students are given the chance to develop their reflective function and hence gain a greater sense of meaning from their experience at school. Essential to this is the teacher-advocates' success in developing positive relationships with the students for whom they take responsibility.

Within the advocacy model as described by Ocean (2001), Neville and Schmidt (2001), Henry et al. (2003) and McCann (2008), the central role played by the advocate is to link the personal attributes of the young person to the education and community systems in a meaningful way. However, unless a student and teacher have a common language it is difficult for either the advocate or the student to develop a strong personal educational narrative. If students are to take responsibility for their own progress, it is incumbent upon us to engage the learner in dialogue around the meaning of their experiences at school, and to hold this dialogue within the phenomenal world of the student.

Knox's notion of 'reflective function', which she developed in the framework of attachment theory, provides a key to understanding the interaction between the teacher-advocate and the student within the advocacy model of student support. The advocacy framework, on its part, provides an approach to supporting the development of the reflective function within the student. Within a secure and reliable relationship the adolescent is able to develop psychologically within the four dimensions listed by Knox: narrative competence, intentionality, appraisal and individuation.

\section{Narrative competence}

In attachment theory as developed by Fonagy et al. (2005) and Knox (2003), narrative competence is perceived to be the basis for the development of a sense of agency. If this is so, it will be a key focus in the work of schools, and therefore of the advocate, to provide the opportunity for the students for whom they have a responsibility to develop the sense that they can make decisions of their own and act on them. Within an educational setting the key issue is the development of a sense of personal agency in the task of learning. The teacher-advocate has a significant role in this.

In the advocacy model the advocate is given a set of tools to assist in developing a productive relationship with a student with a focus on the student's sense of agency. What am I doing at school? Where does this lead? What choices do I have? 
In their study of Year 12 students' reasons for staying at school, Ainley, Batten and Miller (1984) found that personal investment in schooling as a meaningful activity was a key factor.

The Student Achievement Inventory provides students with instant feedback, giving them a language in which to reflect on and discuss their personal learning history, interest, likes, dislikes, hobbies, learning styles and difficulties, their intentions and their achievements. Questionnaires included in the SAI provide a basis for dialogue around a range of issues related to the construction of a personal narrative. Feedback provides profiles of the following:

- home/family context

- personal interests and hobbies

- roles from family, work, school, community, sporting clubs

- responsibilities

- $\quad$ preferred learning style

- attitudes to authority

- $\quad$ attitude to responsibility

- a personal curriculum vitae.

These questionnaires provide a rich background for discussion around the theme of personal agency. What am I doing? Why am I here? What am I good at?

The SAI provides the symbolic language enabling a discussion around the development of the student's personal narrative.

In developing a personal narrative for each student the advocate takes care to build an accurate profile of the student's successes and difficulties. The underlying assumptions on which the students build their sense of success and failure are noted and examined. These assumptions can come from previous schooling experiences, the home and wider social influences. Early experiences are powerful in shaping our stance towards our world, and by the time the student has reached adolescence the student has developed 'working models' (Bowlby 1979) of relationships with adults and of his or her identity as a participant in the school culture. Whether they are functional or dysfunctional, such working models are extremely resilient. Adolescents whose experience has taught them that adults are uncaring or untrustworthy and whose personal narratives proclaim that they are 'losers' will tend to stick to this story regardless of evidence that may contradict it.

Through dialogue around the SAI the teacher-advocate and the student can develop a shared understanding of who this student is and how he or she learns, against a backdrop of the ways others might prefer to learn. Students construct meaning through learning to reflect on their experience within the safe container of a one-toone relationship with a trustworthy adult.

The narrative competence of the student can be progressed by the linking of the information gained from the SAI with the student's schooling and experience of the wider world. By more clearly defining what they have done and what they have 
achieved, an enhanced confidence in their ability to make productive choices can be developed.

\section{Intentionality}

The SAI questionnaires look also to the future, raising such issues as: What do I want? Where am I going? How will I get there?

Knox described this second aspect of reflective function as the 'capacity to pursue goals and desires, that is, to have a mental appetite' (2003, p. 142). With adequately secure attachment the child learns both to acknowledge and understand the intentions of others and to protect and explain their own behaviour, a crucial developmental achievement and a central feature of theory of mind. Adequate psychological development includes a capacity to be mindful of one's own intentions and needs, and mindful also of the intentions and needs of others.

Within the advocacy relationship the concept of intentionality is highlighted in two ways. The first is discussion around the formation of a long-term plan so that the students develop a long-term goal that they have set for themselves. The second is short-term goal setting, which breaks up the more broadly based concepts into weekly actions that need to be achieved. Short-term goals, facilitated by tools in the SAI, can be set in discussion between the advocate and the student. They cover aspects of the student's life in school and community: study, sporting clubs, family, relationships and other aspects of life that are currently important to the student.

The function of the intense goal setting is to make the student aware that by setting and achieving goals on a short-term basis a record of achievement can be developed over a short period of time. If six goals are set and achieved and appraised by the advocate as achieved for each week, then after six weeks 36 goals will have been achieved. At this point the advocate and the student can celebrate the achievement of so many small aspects of developing 'intentionality'.

The setting of long-term goals, while important, can be ineffective unless attention is drawn to these goals on a regular basis. My (BS) experience with the Victorian Managed Individual Pathways Project, which was established following a recommendation from the Kirby review (2001), leads me to believe that many longterm plans are set in such frameworks, but far, far, fewer are regularly reviewed.

The setting of weekly goals ensures that the students have a focus for the week around aspects of their life that require them to achieve or complete particular tasks. In some settings these goals include attendance, relationship with peers, relationships with teachers, family relationships, sporting achievement, learning a new hobby, learning a musical instrument, taking new roles in artistic productions, community work or a personal responsibility at school - as well as achieving higher grades on assignments and ceasing to be disruptive in a classroom. Through the discussion that takes place in the one-to-one relationship the advocate and the student are able to set short-term goals easily and monitor them with the tools available in the SAI. 
If the goals are not reviewed by the advocate then the point of setting the goals may well be missed by the student. For goal setting to become an established mode of operation for the student, constant attention must be given to this aspect of the advocacy relationship for a number of months so that the achievement can be registered with the student and his or her parents. The advocate can after some months change the review of the goal setting from weekly to fortnightly and eventually much longer periods, as weekly goal setting becomes habitual for the student.

The long-term plans developed with the assistance of the SAI tools can also be reviewed on a regular basis. If these plans are not reviewed then the student may well come to see that the plan has little relevance in the educational setting.

Knox argued that intentionality, the capacity to pursue goals and desires, to have a mental appetite, is an essential step in the psychological development of the child and adolescent. The appropriate use of the short-term and long-term goal-setting tools in the SAI has the potential to enhance these capacities significantly in students within an advocacy relationship.

The current setting for the advocacy project is a school system in which there is a move away from classroom-based teaching to a more personalised, computerassisted model of education. This is sometimes assisted by architecture and additional IT resources, but it is not always embraced with enthusiasm by teachers. The advocacy model and the SAI are by design entirely compatible with this innovation. Students are supported to find their own purposes and be motivated by them to engage in schooling on their own behalf, rather than simply out of compliance with the goals of parents and teachers.

\section{Appraisal}

Knox described appraisal as the capacity to evaluate the relative significance of experiences.

Appraisal requires an experience to be appraised. The advocate's stance of nonjudgemental, empathic listening assists the student to evaluate the quality and meaning of both past and current experiences of schooling. The development of a realisation that one has the capacity and the right to judge the meaning and significance of one's experiences, rather than simply accept the appraisals of others, is an essential part of growing up, and starts fairly early in the process. However, children and adolescents who are not supported in this process must either slip into mindless compliance or take a stance of reaction and resistance against those who tell them what they are supposed to think, feel and do. For the adolescent student, the invitation within the advocacy interaction to review and appraise experiences of schooling, work, relationships, desires and emotions is central to their gaining a sense of how they relate to the world. We may believe that adolescents should grow up as people with minds of their own, rather than constantly defer to others' judgements as more valid than their own. However, not all classroom cultures support this process. 
Knox pointed out that appraisal is largely an unconscious process, operating automatically on the basis of habitual 'working models' of what matters in life. However, it can become conscious, through development of the reflective function. Some adolescents are habitually and automatically dependent on the appraisals of others. Others are habitually counter-dependent, reacting with automatic resistance to the appraisals of others. The position of independence, which falls between these two reactive stances, demands a conscious sense of psychological identity, in which appraisals are made on the basis of the evidence, not on the basis of other people's expectations or one's negative reaction to them, and not through the internalisations of other people's appraisals of oneself as 'bad' or 'uncooperative' or 'a loser'. A student's examination of her experience of learning and schooling within a relationship with a trusted adult can make a significant contribution to the development of a sense of 'knowing one's own mind'.

It is necessary for maturing adolescents to develop a sense of meaning in how they perform and relate, and in how other people think and feel as they go about their daily tasks. Within the one-to-one relationship there is an opportunity for the student to gain a strong and realistic sense of self and gain an understanding that others have personal thoughts and feelings that need to be recognised.

In most schools students are appraised in a global fashion and few schools provide the opportunity for extensive individual appraisal which would enable students to appreciate the full meaning or significance of their schooling experiences. Students usually receive reports on their assignments and exams in a collective report issued twice a year. These reports are generally cryptic and provide a minimalist synopsis of the student's achievements in particular subjects.

The advocacy model, including the SAI, provides a methodology and the resources for students to be able to develop a sense of personal appraisal that is far more refined and developed than the appraisal systems we currently see used in schools.

If the goal setting and planning around aspects of the adolescents' learning are given focus within the advocacy relationship, we might arguably expect the productivity of individual students to increase. If this increase is achieved across a large number of students within the school, then school performance will increase. A small change in the way teachers work may produce a relatively large gain in attendance, retention, academic performance and student wellbeing. This should make system administrators pleased indeed.

\section{Individuation}

Individuation, as Knox defined it in this context, is 'the awareness of one's own and other people's independent subjectivity' (2003, p. 156). The achievement of a sense of our own separateness and individuality is associated with a recognition that others have experiences, thoughts, values and emotions that are different from our own. Achieving a sense of separateness enables the child or adolescent to transcend the assumption that he must either control or be controlled by others. Emotions become an expression of self instead of a tool of manipulation. Other people are perceived not only to have their own subjectivity, but are allowed to think different thoughts 
and feel different feelings. Though development of this aspect of reflective function can start early in childhood, not all people manage to achieve it in a lifetime.

The experience of schooling can assist adolescents in this developmental task.

Teachers cannot give adolescents individuation. However, we can construct an educational environment in which the student can be given the opportunity and a set of tools for discovering personal meaning through the development of reflective function.

In a satisfactory advocacy relationship the student gains an understanding of who they are as a learner and as a person, and gains an understanding also that other people (including teachers) may learn differently and react differently to their experiences. It is this independent subjectivity, a personal sense of agency, action, intention and reflection against the background of others' diverse experiences, that needs to be supported by teachers and is particularly reinforced within an advocacy relationship. The SAI includes tools such as the learning preference questionnaire, the personal profile and curriculum vitae which are designed to support the student's individuation.

Schools, at their best, are concerned with the psychological and social development of their students and acknowledge that this development involves more than academic or sporting outcomes as defined by others. However, there is always some tension between the school's need for compliance and the adolescent's need to become an independent, individuated person. Within the advocacy relationship it is hoped that these issues can be addressed and the students can be supported in development of reflective function, so that they are not only able to reflect on their own needs and behaviours, but also to acknowledge that teachers (and schools) have needs and behaviours that make sense within the school's 'field of experience'.

\section{Finding meaning}

When the advocacy project was first designed and piloted in 1999, it was intended to address a deficit in the Victorian public education system. The decline in resources targeting individual learners in high schools had left many students without adequate support at a critical time in their lives, with consequent disengagement from schooling. Research on the outcomes of the project indicated clearly enough that students who were provided with the opportunity to form a relationship with a teacher-advocate were less likely to absent themselves from school and more likely to remain at school for the post-compulsory years (Ocean 2001).

We can argue that through their conversations with their teacher-advocates these students were able to find meaning in their school experience, to the extent that they could see a point in attending school and seeking further qualifications. Though the use of electronic tools in the early implementation of the model was limited, there was some indication that the tools used played a significant part in assisting the students to reflect on their experience and abilities and develop meaningful shortterm and long-term goals. 
The two components of the advocacy model as it is currently being applied in a number of Victorian schools - the one-to-one relationship and the Student Achievement Inventory - are designed to support student engagement in schooling. This is not simply because having a teacher-advocate or learning mentor who provides a secure and reliable relationship makes school a more comfortable place to be. (Students interviewed in evaluating the model have said things like: 'It's nice having an advocate, because now there is a teacher who knows my name and smiles at me'!) Advocacy has more to offer than this. Though the model has an unambiguous focus on the support of students' learning, there is no doubt that it has a very positive impact on the general wellbeing of students (Henry et al. 2003). It achieves this through the student's and advocate's collaboration in constructing a student's personal meaning system - a meaning system in which learning and goals play a significant part. Support for the student's reflection on self, school context and future possibilities is the means to this end. Such reflection is facilitated in a relationship where the trusted adult is prepared to enter the student's world by truly listening, and brings to the conversation not only the skills of a teacher but also the attitude of an advocate.

\section{Conclusion}

It can be readily enough argued, on the evidence of previous research, that the oneto-one relationship with a reliable teacher-advocate has a positive impact on adolescent wellbeing and consequently on school engagement and academic achievement. The current project in Victorian schools focuses on how this positive impact may be further enhanced when supported by appropriate electronic tools.

In this paper we have highlighted a particular aspect of adolescent wellbeing: the development of 'reflective function' in adolescence. We have theorised this within the framework of attachment theory and Rogers' theory of personality and behaviour, both of which point to relationships with significant others as a key factor in personal development. A particular intervention designed to provide adolescents with a reliable attachment has been theorised within this framework.

The implications of attachment theory for adolescent development in the schooling context have only recently become a particular focus of attachment research. Although it is widely acknowledged that adolescents will utilise other figures besides their primary attachment figures in fulfilling their attachment needs, the role of teachers in this regard has yet to be investigated. Nevertheless, it is a promising field for both research and theory, as Riley (2011) indicated in his recent work. The specific contribution that teacher-advocates or learning mentors may make to adolescent development has not to date been explored. Likewise, there are implications in attachment theory for the selection and training of teachers and advocates, who may benefit from an understanding of their own attachment style and its impact on the students for whom they are responsible.

There have been four decades of research on student-teacher relationships, much of it inspired by Rogers' formulations on 'client-centred therapy' and 'student-centred teaching'. There is currently a great deal of rhetoric about 'personalised', 'learnercentred' and 'learner-directed' schooling, and it is within this context that schools 
tend to welcome the advocacy model. Rogers' name is rarely mentioned in this rhetoric, yet his theory of personality and behaviour provides a more solid basis for this innovation than the observation that 'classrooms do not seem to work any more'. In view of the diversity of attitudes towards an innovation that encourages the construction of open 'learning spaces' and 'conversation pits', the abandonment of classrooms and the proliferation of computers, there is room for research on the attachment styles of teachers who embrace or oppose such changes and the compatibility of their attitudes with a 'learner-centred' orientation. There is also room for research into the psychological basis for the enthusiasm or anxiety with which students greet this opportunity. Attachment theory provides a framework for such an investigation.

We have argued the connection between positive one-to-one teacher-student relationships and adolescent psychological development on theoretical grounds. One aim of the current study is to establish whether there is an empirical basis for this assertion. The study is limited in that it does not include the categorisation of students in terms of secure or insecure attachment. However, the research approach includes case studies to record the 'learning narratives' of students deemed to be at risk. It is hoped that this will provide data on whether teacher-advocates figure positively in the attachment hierarchies of such students and how this can be achieved.

All of these issues are complex. Acknowledging their interrelationship and dealing with all of them at once, which is the approach of advocacy, substantially increases the complexity of the project. However, we would argue that it also substantially increases the impact of the approach.

\section{References}

Ainley, J, Batten, M and Miller, H 1984, Staying at high school in Victoria, ACER Monograph No. 23, Australian Council for Research in Education, Melbourne.

Ainsworth, M 1989, ‘Attachments beyond infancy’, American Psychologist, vol. 44, pp. 709-716.

Allen, JP and Land, DL 1999, 'Attachment in adolescence' in Handbook of attachment: theory, research, and clinical applications, ed. J Cassidy and PR Shaver, Guilford Press, New York, pp. 319-335.

Baker, J, Terry, T, Bridges, R and Winsor, A 1997, 'Schools as caring communities: a relational approach to school reform', School Psychology Review, vol. 26, pp. 576-588. 
Bartholomew, K and Horowitz, LM 1991, 'Attachment styles among young adults: a test of a four-category model', Journal of Personality and Social Psychology, vol. 61, no. 2, pp. 226-244.

Bliss, LB 2002, 'An instrument for the assessment of study behaviours of high school students', paper presented at the annual meeting of the American Educational Research Associations, New Orleans, LA, 5 April.

Bliss, LB and Mueller, RJ 1993, 'An instrument for the assessment of study behaviors of college students', Reading Research and Instruction, vol. 32, no. 4 , pp. 46-52.

Blos, P 1967, 'The second individuation process of adolescence', Psychoanalytic Study of the Child, vol. 22, pp. 162-186.

Bowlby, J 1979, The making and breaking of affectional bonds, Tavistock, London.

Bowlby, J 1982 [1969], Attachment and loss, vol. 1, Basic Books, New York.

Bowlby, J 1990, The secure base, Basic Books, New York.

Brooks, M, Milne, C, Paterson, K, Johansson, K and Hart, K 1997, Under-age school leaving, Clearing House for Youth Studies, Hobart.

Department of Education, Science and Training 2001, Footprints to the future: summary report from the Prime Minister's Youth Pathways Action Plan Taskforce 2001, DEST, Canberra.

Department of Education, Training and Youth Affairs 2001a, Doing it well: case studies of innovation and best practice in working with at-risk young people, DETYA, Canberra.

Department of Education, Training and Youth Affairs 2001b, National evaluation report: Full Service Schools Program 1999/2000, DETYA, Canberra.

Drapela, L 2006, 'Investigating the effects of family, peer and school domains on post-dropout drug use', Youth Society, vol. 37, no. 3, pp. 316-347.

Everson, HT, Weinstein, CE and Laitusis, V 2000, 'Strategic learning abilities as a predictor of academic achievement', paper presented at the annual meeting of the American Educational Research Association, New Orleans, LA, 24-28 April. ERIC Document Reproduction Service No. ED441837.

Fashola, O and Slavin, R 1998, 'Effective dropout prevention and college attendance programs for students placed at risk', Journal of Education for Students Placed at Risk, vol. 3, pp. 159-183. 
Fiscella, K and Kitzman, H 2009, 'Disparities in academic achievement and health: the intersection of child education and health policy', Pediatrics, vol. 123, no. 3, pp. 1073-1080.

Fonagy, P, Gergely, G, Jurist, E and Target, M 2005, Affect regulation, mentalization, and the development of the self, Other Press, New York.

Fraser, B, Walberg, H, Welch, W and Hattie, J 1987, 'Syntheses of educational productivity research', International Journal of Educational Research, vol. 11, pp. 145-252.

Henry, J, Barty, K and Tregenza, K 2003, Connecting through the middle years: final evaluation report, Department of Education and Training, Melbourne.

Holden, E and Dwyer, P 1992, Making the break: leaving school early, Institute of Education, University of Melbourne, Melbourne.

Karnes, FA and Bean, SM 1990, Process skills rating scales, PRO-ED, Austin, TX.

Knox, J 2003, Archetype, attachment, analysis: Jungian psychology and the emergent mind, Brunner-Routledge, New York.

Lamb, S, Walstab, A, Teese, R, Vickers, M and Rumberger, R 2004, Staying on at school: improving student retention in Australia, Report for the Queensland Department of Education and Arts.

McCann, P 2008, A theatre of the observed: a study of adolescent meaning-making, $\mathrm{PhD}$ thesis, La Trobe University, Melbourne.

McElhaney, K, Allen, J, Stephenson, J and Hare, A 2009, 'Attachment and autonomy during adolescence' in Handbook of Adolescent Psychology, ed. R Lerner and L Steinberg, Wiley, New York.

McIntyre, J, Freeland, J, Melville, B and Schwenke, C 1999, Early school leavers at risk, National Centre for Education Research, Leabrook, SA.

Michael, WB, Michael, JJ and Zimmerman, WS 1985, Study attitudes and methods survey revised short form, EdITS-Educational and Industrial Testing Service, San Diego.

Ministerial Review of Post Compulsory Education and Training Pathways in Victoria 2000, The Kirby Report, Department of Education and Training, Victoria.

Mukherjee, D 1999, Strategies and programs that improve educational outcomes for students at risk: a review of the literature, Australian Centre for Equity Through Education, Sydney. 
Neville, B and Schmidt, B 2001, 'Student engagement: the advocacy program', Teacher Learning Network, vol. 8, no. 3, pp. 26-29.

Ocean, J 2001, Advocacy 2000 evaluation report, Ocean Consulting, Melbourne.

Ocean, J and Caulley, D 2000, The advocacy project 1999: final report to the Department of Education, Employment and Training, La Trobe University, Melbourne.

Olivárez, A and Tallent-Runnel, MK 1994, 'Psychometric properties of the Learning and Study Strategies Inventory - High School Version', Journal of Experimental Education, vol. 62, pp. 243-257.

Osterman, K 2000, 'Students' need for belonging in the school community', Review of Educational Research, vol. 70, no. 3, pp. 323-367.

Pomeroy, E 1999, 'The teacher-student relationship in secondary school', British Journal of the Sociology of Education, vol. 20, no. 4, pp. 465-483.

Pettet, B and Western, B 2004, 'Mass imprisonment and the life course: race and class inequality in US incarceration', American Sociological Review, vol. 69, no. 2, pp. 151-169.

Rice, KG 1990, 'Attachment in adolescence: a narrative and meta-analytic review', Journal of Youth and Adolescence, vol. 19, no. 5, pp. 511-538.

Riley, P 2011, Attachment theory and the teacher-student relationship, Routledge, London.

Robinson, L and Lamb, S 2009, How young people are faring: national report on the learning and work situation of young Australians, Foundation for Young Australians, Melbourne.

Rogers, CR 1951, Client-centred therapy: its current practice, implications and theory, Houghton Mifflin, Boston.

Rogers, CR 1961, On becoming a person, Houghton Mifflin, Boston.

Rogers, CR 1983, Freedom to learn for the eighties, Charles Merrill, Columbus, $\mathrm{OH}$.

Rumberger, R. 1987, 'High school dropouts: a review of issues and evidence', Review of Educational Research, vol. 57, no. 2, pp. 101-121.

Social Inclusion Unit 2006, Making the connections: School Retention Action Plan, Department of Premier and Cabinet, Adelaide, SA. 
Stokes, H 2000, Out of education: a report for the Victorian full service schools program, Department of Education, Employment and Training, Melbourne.

Van Alphen, S 2009, 'The educational quality of early school leavers and the crossnational variation of their income disadvantage', Educational Research and Evaluation, vol. 15, no. 6, pp. 543-560.

Weinstein, CE and Palmer, DR 1990, LASSI-HS: Learning and Study Strategies Inventory - High School Version, H \& H Publishing, Clearwater, FL3. 